\title{
COMPOSIÇÃO QUÍMICA E ADEQUAÇÃO DA ALIMENTAÇÃo OFERECIDA AOS PRÉ-ESCOLARES DE UMA INSTITUIÇÃO BENEFICENTE DE MANAUS, AMAZONAS, BRASIL.
}

\author{
Lúcia K.O. YUYAMA', Alba L.V. VASQUEZ', Jaime P.L. AGUIAR', Sonja H.M. \\ MACEDO $^{1}$, Lina YONEKURA ${ }^{1}$, Dionisia NAGAHAMA ${ }^{1}$, Cyntia W. FONSECA ${ }^{2}$
}

RESUMO - Determinou-se os constituintes nutricionais da alimentação de pré-escolares de uma creche de Manaus, AM., seguida da adequação da mesma. Foi realizada a coleta da alimentação (desjejum, almoço e lanches), por meio da porção em duplicata, e analisada quimicamente. Os alimentos freqüentemente consumidos foram feijão $(25,1 \%)$, leite com café (19.9\%), chá/sucos/refrigerantes (13,9\%) e arroz (10,3\%). A adequação protéica e energética foram de $126,1 \%$ e $32,42 \%$, considerando as necessidades para as faixas etárias de 1 a 3 anos e $84 \%$ e $23,4 \%$ para o intervalo de 4 a 6 . A quantidade de fibra total encontrada na dieta analisada foi baixa (5,6 g/dia). A adequação de consumo de $\mathrm{Cu}(431.8 \%$ e $293.6 \%)$ e $\mathrm{Na}(512 \%$ e $384 \%)$, considerando as faixas de 1 a 3 anos e 4 a 6 anos, respectivamente. $\mathrm{Ca}, \mathrm{Zn}$ e Fe foram limitantes, com adequação inferior a $50 \%$.

Palavras-chave: dieta, nutrição, composição centesimal.

Chemical Composition and Diet Adequacy Offered to Pre-School Children at One Beneficent Institution in Manaus, Amazonas, Brazil.

ABSTRACT - The nutritional constituints of the food offered to pre-school children at one Beneficent Institution in Manaus, AM., was determined as well as its nutrient adequacy ratio. Duplicate food samples were collected at (breakfast, lunch and snacks) and chemically analyzed. The most frequently consumed foods were beans $(25,1 \%)$, milk with coffee $(19.9 \%)$, tea/juice/ soda $(13,9 \%)$ and rice $(10,3 \%)$. Protein and energy adequacy was $126,1 \%$ and $32,42 \%$ respectively, considering the needs for the age group of 1 to 3 years, and $84 \%$ and $23,4 \%$ for the 4 to 6 years group. The amount of fiber total in the diet was low $(5,6 \mathrm{~g} / \mathrm{dia})$. The $\mathrm{Cu}$ and $\mathrm{Na}$ adequacy was $431.8 \%$ and $293.6 \%$ and $512 \%$ and $384 \%$ respectively, considering the needs for the age group and the $\mathrm{Ca}, \mathrm{Zn}$ and $\mathrm{Fe}$ was inferior to $50 \%$.

Key-words: diet, nutrition, centesimal composition.

\section{INTRODUÇÃO}

Nas últimas décadas, a rápida urbanização da população brasileira e a sua concentração nas grandes metrópoles assim como as recentes mudanças no hábito alimentar como modismo das refeições rápidas, nem sempre equilibradas do ponto de vista nutricional, constituem aspectos sérios e preocupantes, ao lado da precária situação sócio econômica, cultural e ambiental, revolucionando a alimentação do brasileiro (Dutra de Oliveira et al., 1996). Entretanto a alimentação das crianças não está limitada só no lar, mas também nas creches ou pré-escolas onde poderão receber até quatro refeições por dia satisfazendo, assim, mais da metade das necessidades nutricionais extra lar, o que reflete na melhoria da qualidade de vida, em especial das familias de baixo poder aquisitivo.

\section{A Organização Mundial da}

${ }^{1}$ Instituto Nacional de Pesquisas da Amazônia- Coordenação de Pesquisas em Ciências da Saúde. Av. André Araújo, 1756, Aleixo, Manaus/AM. CEP: 69083-000. E- mail: yuyama@inpa.gov.br

${ }^{2}$ Fundação Hospitais e Creches do Amazonas - HOCRE. Av. Gen. R. Otávio, 510, Manaus, AM.

CEP: 69077-000. 
Saúde (OMS), revela que cerca de 300 milhões de crianças no mundo apresentam retardo no crescimento e nos países em desenvolvimento entre 20 a $75 \%$ das crianças com menos de cinco anos padecem de desnutrição energético-protéica (Nnakwe, 1995).

No Amazonas, a realidade nutricional das populações repercute de forma preocupante, pois de acordo com os indicadores utilizados, deixa implícito o debilitado estado geral de saúde e a triste realidade nutricional, social e econômica a que historicamente está submetida a população Amazônida (Alencar et al., 1996).

O consumo alimentar é um indicador de grande importância para o conhecimento da cadeia causal da desnutrição (Galisa et al.,1996). E a avaliação dietética por sua vez, é um dos parâmetros relevantes para se traçar o perfil nutricional de um grupo populacional, pois por meio destes estudos pode-se obter a identificação de grupos de alto risco e monitoramento de programas apropriados de intervenção nutricional.

Quando se fala em macro e microelementos minerais, a avaliação dietética por meio de inquéritos e composição de alimentos deixam a desejar, por carecerem de informações quanto a composição desses elementos em tabelas de composição de alimentos, não condizendo portanto, com a realidade do local estudado, sendo desse modo recomendada a análise química laboratorial em duplicata (Abdula, 1979).

Considerando a escassez de informações quanto ao perfil dietético em pré-escolares da Região Amazônica, em especial de creches de Manaus, e a relevância destas informações para o processo de prevenção e/ou intervenção nutricional, determinou-se a composição centesimal, fibra alimentar solúvel e insolúvel e elementos minerais na dieta de préescolares freqüentadores da Fundação Hospitais e Creches do Amazonas, assim como a adequação dos mesmos.

\section{MATERIAL E MÉTODOS}

Foram analisadas as refeições servidas aos pré-escolares da Fundação Hospitais e Creches do Amazonas (HOCRE), no desjejum, almoço e lanches, obtidas por meio da porção em duplicata, por um periodo de 18 dias (Maio a Junho de 1997). Os alimentos foram coletados individualmente em sacos plásticos, sendo transportados ao Laboratório de Nutrição do Instituto Nacional de Pesquisas da Amazônia (INPA), pesados e distribuídos em bandejas de aço inoxidável, onde se procedeu a determinação do teor de umidade em estufa com circulação forçada de ar a $60^{\circ} \mathrm{C}$. As dietas, após a secagem, foram pulverizadas em moinho de facas de aço inoxidável e acondicionadas em potes de polietileno previamente desmineralizados com ácido nítrico a $30 \%$. As determinações quanto à composição quimica seguiram as recomendações da (AOAC, 1995). Quanto ao teor de fibra alimentar solúvel, insolúvel e total, seguiu-se o método enzimático gravimétrico de (ASP et al., 1983). O valor energético foi calculado a partir 
dos teores das frações protéica, lipídica e glicídica, utilizando-se os "fatores Atwater", especificos, que levam em consideração o calor da combustão, 4 , 9 e 4 respectivamente. A determinação dos elementos minerais macro $(\mathrm{Ca}, \mathrm{Na}$, $\mathrm{K}, \mathrm{Mg}$ ) e micro ( $\mathrm{Fe}, \mathrm{Zn}, \mathrm{Cu}, \mathrm{Mn}$ ) o método espectrofotométrico de absorção atômica (Perkin Elmer 3000 AAS) após digestão por via úmida utilizando ácido nitrico e perydrol (IAL, 1988). Como material de referência utilizou-se Bovine Liver (NIST-SRM 1547), de acordo com as recomendações de (Cornelis, 1992; Delves, 1992).

Para o cálculo de adequação nutricional seguiu-se as recomendações da (NAS/NRC, 1989), considerando as faixas etárias de 1 a 3 anos e 4 a 6 anos.

\section{RESULTADOS E DISCUSSÃO}

De acordo com os resultados obtidos verificou-se que os alimentos freqüentemente consumidos foram: feijão, leite com café, chá/suco/ refrigerantes e arroz (Tab. 1). Os cardápios foram extremamente diversificados no que diz respeito ao prato principal servido no almoço e no desjejum, o tradicional café com leite e pão com manteiga (Tab. 1). Entretanto, quando comparados os alimentos freqüentemente consumidos pelos pré-escolares da HOCRE com os do Municipio de Barcelos, de acordo com os estudos de Yuyama et al. (1997), foram muito distintos, mas semelhantes aos achados em outras regiões (Priore et al., 1996).

$\mathrm{O}$ valor calórico médio da dieta dos pré-escolares da HOCRE foi de
421,49 Cal e representou 32 e $23 \%$ das necessidades calóricas diárias respectivamente para crianças de 1-3 e 4 - 6 anos (Tab. 2). Essa limitação calórica foi também observada na alimentação de crianças de um bairro pobre de Papua Guinea (Gibson et al., 1991). Apesar das semelhanças destes resultados, salienta-se que o jantar não foi computado por não fazer parte da rotina da creche, favorecendo assim, as condições da alimentação oferecida aos pré-escolares da HOCRE. A contribuição calórica diária dos nutrientes foi de $19,14 \%$, oriundos de proteinas, $18,81 \%$ de lipídios e 62,05 de glicídios, indicando desequilibrio na oferta energética de proteinas na alimentação considerada. $\mathrm{O}$ teor de fibra foi baixo para a alimentação analisada (Tab. 3).

A adequação protéica foi superior a $100 \%$ para crianças de 1 a 3 anos e $84 \%$ para o grupo de 4 a 6 anos (Tab. 2). Estes resultados se assemelham aos encontrados por (Yuyama et al., 1997). Isto demonstra que o problema dos pré-escolares tanto da área rural como urbana do Estado do Amazonas é calórico e por conseguinte também protéico, pois apesar de uma adequação aparente de proteina, na deficiência de calorias, a proteína é desviada para fins energéticos em detrimento à função plástica. Tal comprovação necessita de estratégias de ação no que se refere à oferta calórica, a fim de se evitar a desnutrição energético-protéica, uma das deficiências nutricionais de maior abrangência epidemiológica (Batista 
Tabela 1. Preparações freqüentemente consumidas pelos pré-escolares da Creche HOCRE, Manaus-AM. (Maio/Junho/1997).

\begin{tabular}{lccc}
\hline Preparaçăo por Refeição & Frequência & Per capita & $\%$ \\
\hline Desjejum & 18 & 107,7 & 19,9 \\
Leite com café & 18 & 25,8 & 4,8 \\
Påo com manteiga & & & \\
Almoço & 14 & 71,7 & 10,3 \\
Arroz & 14 & 24,1 & 4,5 \\
Carnes e ovos & 15 & 162,6 & 25,1 \\
Feijăo com legumes & 3 & 148,3 & 4,6 \\
Sopa & 2 & 23,1 & 0,5 \\
Salada de alface/tomate & 2 & 85,4 & 1,8 \\
Macarråo & 1 & 6,03 & 0,1 \\
Batata frita & & & \\
Sobremesa & 9 & 36,9 & 3,4 \\
Frutas in natura & & & \\
Lanche & 11 & 122,8 & 13,9 \\
Chá/sucos/retrigerantes & 5 & 103,5 & 5,3 \\
Mingaus/nescau & 10 & 35,5 & 3,7 \\
Bolacha/pudim/bolo & 3 & 60,4 & 1,9 \\
\hline Sorvete/creme/vitaminada & & & \\
\hline
\end{tabular}

Tabela 2. Quantidade per capita de calorias e nutrientes e percentual de adequação da alimentação de pré escolares da HOCRE. (Maio/Junho/1997).

\begin{tabular}{lcc}
\hline \multirow{2}{*}{ Nutriente } & Per capita e\% de adequaçăo por idade* \\
& $1-3$ anos & 4.6 anos \\
\hline Calorias (Cal) & $421,5(32,4)$ & $421,5(23,4)$ \\
Proteina (g) & $20,2 \mathrm{~g}(126,1)$ & $20,2 \mathrm{~g}(84,0)$ \\
$\mathrm{Na}(\mathrm{mg})$ & $1151,9(512,0)$ & $1151,9(384,0)$ \\
$\mathrm{K}(\mathrm{mg})$ & $838,0(83,8)$ & $838,0(59,8)$ \\
$\mathrm{Ca}(\mathrm{mg})$ & $162,8(20,3)$ & $162,8(20,3)$ \\
$\mathrm{Mg}(\mathrm{mg})$ & $95,1(118,9)$ & $95,1(79,3)$ \\
$\mathrm{Cu}(\mathrm{mg})$ & $3,7(431,8)$ & $3,7(293,6)$ \\
$\mathrm{Fe}(\mathrm{mg})$ & $4,8(48,1)$ & $4,8(48,1)$ \\
$\mathrm{Mn}(\mathrm{mg})$ & $1,4(112,0)$ & $1,4(80,0)$ \\
$\mathrm{Zn}(\mathrm{mg})$ & $3,7(36,7)$ & $3,7(36,7)$ \\
\hline
\end{tabular}

Ingestão alimentar média diária $540,8 \mathrm{~g}$
- National Academy of Sciences, 1989

Tabela 3. Composição química e energia da dieta de pré-escolares da HOCRE. (Maio/Junho/1997).

\begin{tabular}{cccccccc}
\hline $\begin{array}{c}\text { Umidade } \\
(\%)\end{array}$ & $\begin{array}{c}\text { Nifext } \\
(\mathrm{g})\end{array}$ & $\begin{array}{c}\text { Proteína } \\
(\mathrm{g})\end{array}$ & $\begin{array}{c}\text { Lipídio } \\
(\mathrm{g})\end{array}$ & $\begin{array}{c}\text { Cinza } \\
(\mathrm{g})\end{array}$ & $\begin{array}{c}\text { Fibra } \\
\text { insolúvel } \\
(\mathrm{g})\end{array}$ & $\begin{array}{c}\text { Fibra } \\
\text { solúvel } \\
(\mathrm{g})\end{array}$ & $\begin{array}{c}\text { Calorias } \\
(\text { Cal) }\end{array}$ \\
77,7 & 65,4 & 20,2 & 8,8 & 4,4 & 5,6 & 0 & 421,6 \\
\hline
\end{tabular}

Filho \& Rissin, 1993). A adequação de consumo de $\mathrm{Cu}$ e $\mathrm{Na}$ foram superiores a $100 \%$ nas duas faixas etárias e Mn no grupo de 1 a 3 anos (Tab. 2). Os demais elementos minerais apresentaram adequação inferior a $50 \%$, sendo $\mathrm{Ca}, \mathrm{Zn}$ e $\mathrm{Fe}$ os elementos extremamente limitantes (Tab. 2). Apesar da escassez dos estudos envolvendo creches da região Amazônica, percebe-se que a situação não é muito diferente quando comparada com estudos de Nagahama et al. (1990), bem como os de préescolares de diferentes regiões, os quais demonstram deficiências de macro e micronutrientes e algum grau de desnutrição do grupo de estudo (Santos, 1995; Maihara, 1996; Ramalho, 1996; Sato, 1996; Silva \& Sturion, 1996).

Considerando que ingestões limitadas de nutrientes têm implicações no desenvolvimento do indivíduo, na saúde e no bem estar geral, os estudos quanto à educação nutricional também são fundamentais, desde que haja a conscientização e o comprometimento da equipe multidisciplinar das instituições, conforme o estudo da análise da eficiência de um programa de educação nutricional de (Galisa et al., 1996). 


\section{CONCLUSÕES}

Conclui-se que a dieta de préescolares da creche HOCRE foi diversificada, especialmente, em relação ao prato principal, apesar do baixo consumo de frutos e verduras. A alimentação considerada (desjejum, almoço e lanche) apresentou déficit energético, baixo teor de fibra alimentar, e os microelementos minerais é preocupante, por estarem muito abaixo do recomendado, apesar da não inclusão do jantar.

\section{AGRADECIMENTOS}

Ao Dr. Charles R. Clement pela revisão do abstract.

\section{Bibliografia citada}

Abdulla, M.; Andersson, I.; Belfrage, P.; Dencker, I.; Jagerstad, M.; Melander, A.; Norden, A.; Scherstén, B.; Thulin, T.; Akesson, B. 1979. Assesment of food consumption. Scand. J. Gastroenterology., 14(52): 28-41.

Alencar, F. H.; Yuyama, L. K. O.; Nagahama, D. 1996. Diagnóstico da realidade nutricional das populações do Amazonas. In: Congresso nacional da SBAN, São Paulo. IV Congresso Nacional da Sociedade Brasileira de Alimentação e Nutrição: Sociedade Brasileira de Alimentação e Nutrição, p.28

Asp, N. G.; Johansson, C. G.; Hallmer, H.; Siljestrom, M. 1983. Rapid enzymatic assay of insoluble and soluble dietary fiber. J. Agric. Food. Chem., Washington, 31: 476-482.

AOAC. 1995. Association Of Official Analytical Chemists/ Official methods of analyses. 16 ed., Arlington. $1141 \mathrm{p}$.

Batista Filho, M.; Rissin, A. 1993. Deficiências nutricionais: Ações especificas do setor
Saúde para o seu controle. Cad. Saúde Públ., 9(2):130-135.

Cornelis, R. 1992. Use de references materials in trace element analisy of foodstuffs. Food Chem., 43: 307-313.

Delves, H. T. 1992. Sample preparation handling. Food Chem., 43: 337-281.

Dutra de Oliveira, J. E.; Cunha, S. F. C.; Marchini, J. S. 1996. A desnutrição dos pobres e dos ricos. São Paulo: Savier, 123p.

Galisa, M. S.; Biscolla, M. O. M.; Moreira, V. 1996. Análise da eficiência de um programa de educação nutricional. $O$ Mundo da Saude, 20(7): 230-232.

Gibson, R. S.; Heywood, A.; Yaman, C.; Schlstrom, A.; Thompson, L. U.; Heywood, P. 1991. Growth in children from the Wosera subdistrict, papua New Guinea, in relation to energy and protein intakes and zinc status. Am. J. Clin. Nutr, 53:782-789.

IAL. 1985. Instituto Adolfo Lutz. Normas analiticas do Instituto Adolfo Lutz. 3 ed. São Paulo, 1, 533p.

Maihara, V. A. 1996. Avaliação do conteúdo de elementos essenciais e tóxicos em dietas de crianças e idosos pelo método de análise por ativação com nêutrons. São Paulo. Tese Doutorado em Tecnologia Nuclear - Instituto de Pesquisas Energéticas e Nucleares-IPEN/ USP. $150 \mathrm{p}$.

Nagahama, D.;Marinho, H. A.; Rocha, Y.; Ferraroni, M. J. R.; Silva, N. B.; Castro, J. S.; Onety, J. A. 1990. Avaliação nutricional e alimentar de pré-escolares de uma creche de Manaus e a influência da entidade no estado nutricional de sua população. Acta Amazônica., 20: 119-29.

NAS/NRC. 1989. National Academy Of Science/National Research Council. Recommended Dietary Allowances. 10 ed., Washington, $284 \mathrm{p}$.

Nnakwe, N. 1995. The effect and causes of protein-energy malnutrition in Nigerian children. Nutr: Res., 15(6): 785-794.

Priore, S.; Franceschini, S.; Schmitz, B.; Pequeno, N.; Magni, P.; Devincenzi, M.; 
Sigulem, D. M. 1996. Caracterização dietética de crianças menores de seis anos atendidas pelo Projeto Favela - UNIFESP/ EPM. In: Congresso Nacional da SBAN, São Paulo. IV Congresso Nacional da Sociedade Brasileira de alimentação e Nutrição: Sociedade Brasileira de Alimentação e Nutrição. p.62

Ramalho, A. 1996. Diagnóstico do estado nutricional de vitamina $\mathrm{A}$ em préescolares atendidos na rede pública de saúde do município do Rio de Janeiro. In: Congresso Nacional da $S B A N$, São Paulo. IV Congresso Nacional da Sociedade Brasileira de alimentação e Nutrição: Sociedade Brasileira de Alimentação e Nutrição. p.20.

Santos, L. M. P.; Assis, A. M. O.; Baqueiro, C. M.; Quaglia, G. M. C.; Morris, S. S.; Barreto, M. L. 1995. Situação nutricional e alimentar de pré-escolares no semi-árido da Bahia (Brasil): I. Avaliação antropométrica. Rev. Saúde Públ., 29(6): 463-471.

Sato, K.; Torres, M. A. A.; Pereira, R. T.; Souza Queiroz, S. 1996. Anemia carencial ferropriva (ACF) em crianças matriculadas em creches, pré-escolas $\mathrm{e}$ escolas do municipio de Matão, SP. In: Congresso Nacional da SBAN, São Paulo. IV Congresso Nacional da Sociedade Brasileira de alimentação $\mathrm{e}$ Nutrição: Sociedade Brasileira de Alimentação e Nutrição. p.29.
Silva, M. V.; Sturion, G. L. 1996. Avaliação antropométrica de crianças dos centros educacionais e creches da Prefeitura Municipal de piracicaba, SP. In: Congresso Nacional da SBAN, São Paulo. IV Congresso Nacional da Sociedade Brasileira de alimentação e Nutrição: Sociedade Brasileira de Alimentação e Nutrição. p.15.

Yuyama, L.K.O; Aguiar, J.P.L.; Alencar, F.H.; Macedo, S. H. M.; Fávaro, D. L. T. 1996. Avaliação nutricional da dieta de pré-escolares do município de Barcelos, AM. In : Congresso Brasileiro De Pediatria, 30, 1997, Rio de Janeiro. Anais do XXX Congresso Brasileiro de Pediatria: Sociedade Brasileira de Pediatria, 1997. p.145 